\title{
A Teoria da Interpretação \\ e a Hermenêutica Bíblica \\ de Paul Ricoeur
}

Arquivo recebido em

2 de outubro de 2012

e aprovado em

15 de novembro de 2012

\section{Resumo}

Esta análise tem por objetivo articular os temas, as fontes bibliográficas e as proposições feitas por Paul Ricoeur nas duas obras - Teoria da interpretação (1973) e A

* Professora da Universidade Federal dos Vales do Jequitinhonha e Muruci; Doutora em Teoria e História Literária e Pós-doutora na me ma área, pela UNICAMP. Doutoranda em Ciência da Religião, pela UFJF. Principais trabalhos publicados: SEVERO, C. G. . Mikhail Bakhtin, Paul Ricoeur e Hannah Arendt: Diálogos em Torn do Espaço Público e das Linguagens. Revista da ANPOLL, p. 50-72, 2010; Paul Ricoeur, Michael Riffaterre e Gérard Genette: Considerações Acerca do Duplo Regime do Objeto Literário. Revista Pesquisa em Foco em Educação e Filosofia, v. 3, p. 14-29, 2010; Tragédia, Epopéia e Lírica: As Narrativas das Mulheres do Antigo Testamento. Mandrágora (São Bernardo do Campo), v. 1 \$, p. 80-90, 2009; Mário de Andrade e o Ócio Produtivo. Raído (UFGD), v. 3, p. 53-63, 2009; "Mi mesis Tripartida, Uma Leitura Hermenêutica de "O Almada" de Machado de Assis". Revista da ANPOLL, p. 109-124, 2008; Paul Ricoeur e o paradigma da tradução. Cerrados (UnB), v. 23, p. 101-109, 2007; Mário de Andrade: A Poética da Alteridade. Sínteses (UNICAMP), Editora da Unicamp, Mário de Andrade: inclusão da diversidade. Revista Conexão Letras, v. 2, p. 120-145, 2006; Mário de Andrade et Paul Ricoeur: Poesie et A térité. Éthiopiques, Dakar - Senegal, v. 75, n.1, p. 1-5, 2005; A jorobabel marioandradina: poesi 319-331, 2003; Poesia e sagrado: da Unicamp, v. 1, n.1, p. 299-315, de amor pleno nas poesias de Márid

2002; SPERBER, Suzi Frankl (Q possível. Dourados: EDUFGD, 2011 sobre identidade, alteridade, ética, pol tica e interdisciplinaridade. São Carlos: Pedro \& João Editores, 2010; Explicar e compreender: por uma teoria literária teológica-religiosa. In: Suzi Frankl Sperber. (Org.). Presença do sagrado na literatura. Questões teóricas e de hermenêutica. 1ed.Campinas: PublielUnicamp, 2011, p. 11-21; Religiosidade e estética: a transposição da identidade pessoal em identidade poética na poesia de José Régio. In: Jérri Roberto Marin. (Org.). Religiões e identidades. Dourados:

Editora UFGD, 2011, p. 309-328 Paul Ricoeur e a orientação ética das narrativas ficcionais: um problema hermenêutico. In: Adna (andido de Paula; Suzi Frankl Sperber. (Org.). Teoria Literária e Hermenêutica Ricoeuriana: Um Diá ogo Possível. 1ed.Dourados: Editora UFGD, 2011, p. 195-214. 
hermenêutica bíblica (2000). O interesse desta proposição, para o debate sobre a "Hermenêutica de Paul Ricoeur", é observar os pontos de contato e de distanciamento relativos à aproximação entre a Literatura e a Teologia, ou ainda, entre a Hermenêutica Literária e a Hermenêutica Bíblica.

Palavas-chave: Ricoeur; Hermenêutica; Interdisciplinaridade.

\section{Abstract}

This analysis aims to articulate the themes, the bibliographic sources and propositions made by Paul Ricoeur in two works - Theory of Interpretation (1973) and The Biblical hermeneutics (2000). The interest of this proposition for the debate about the "Hermeneutics of Paul Ricoeur," is to observe the points of contact and distance on the approximation between the Literature and Theology, or even between the Literary Hermeneutics and Biblical Hermeneutics.

Keywords: Ricoeur; Hermeneutics; Interdisciplinarity.

\section{Uma questão interdisciplinar}

ara Paul Ricoeur, toda teoria de abordagem de objetos a serem analisados deveria sempre pensar os limites de sua própria proposição estando assim aberta ao diálogo com outras linhas de pensamento, às vezes, rivais. Foi o que ele fez com a fenomenologia e a hermenêutica, com a psicanálise e o marxismo, e com a filosofia e a literatura, entre outras relações dialógicas. O caráter altamente positivo do conflito das interpretações reside na possibilidade de crescimento e fortalecimento de duas ou mais áreas de saber em conflito, visto que o debate permite um olhar outro sobre o próprio discurso, sobre suas aporias. Para que a interdisciplinaridade seja produtiva é preciso considerar alguns pressupostos: (i) as duas, ou mais, disciplinas envolvidas têm vocabulários, pressuposições, prioridades, referências e critérios diferentes; (ii) disciplinas diferentes têm, cada uma, suas próprias sub-culturas e as diferenças são antes exacerbadas que atenuadas pela existência de semelhanças superficiais, como por exemplo, termos idênticos utilizados com sentidos bem diferentes; (iii) é preciso que as disciplinas envolvidas estejam preparadas para aprender umas com as outras, sem se colocarem, cada uma, na posição de quem oferece uma lição, de quem 
vai acrescentar um ensinamento à outra, sem proposta de reciprocidade.

Os pontos de contato entre os discursos teológico, religioso, místico e literário só podem ser observados naquilo que se manifesta, que se configura como objeto de análise comum às áreas de conhecimento, que é a linguagem: verbal e não-verbal. Portanto, é necessário configurar um suporte teórico de análise deste objeto, sem, contudo, desrespeitar sua natureza, no entendimento de cada disciplina colocada, aqui, em diálogo. É, nesse sentido, que este trabalho propõe, inspirado na concepção da hermenêutica proposta por Ricoeur, perceber as aproximações e os distanciamentos entre uma hermenêutica bíblica e uma hermenêutica literária. Para tanto, serão consideradas, aqui, duas de suas obras: Teoria da interpretação (1976) e A hermenêutica bíblica (2000).

\section{A hermenêutica ricoeuriana1}

Ricoeur dialogou com os autores da tradição dos estudos hermenêuticos, Schleiermacher, Dilthey, Gadamer, e incorporou alguns de seus elementos à sua própria concepção do ato interpretativo enquanto fenômeno. Inicio essa incursão da hermenêutica proposta por Ricoeur onde ele mesmo considerou tomar um caminho próprio, quando, diferentemente de Heidegger, opta pela via longa no processo de enxerto [la greffe] da fenomenologia na hermenêutica. Trata-se de um percurso que passa por considerações linguísticas e semânticas. A fim de compreender a epistemologia da interpretação, Ricoeur inicia sua investigação com uma reflexão sobre a exegese e segue problematizando diferentes processos interpretativos, tais como, o método da história, a psicanálise e a fenomenologia da religião, tendo como horizonte, uma ontologia da compreensão. O primeiro procedimento defendido por Ricoeur, para a realização dessa empreitada, é a renuncia à idéia de que a hermenêutica

1. Esta introdução foi amplamente apresentada e discutida no artigo: PAULA, Adna Candido de. "A Teia Dialógica da Teoria Literária: uma proposição hermenêutica". In: XI Congresso Internacional da Associação Brasileira de Literatura Comparada, 2008, São Paulo. Anais do XI Congresso Internacional da ABRALIC. São Paulo: ABRALIC, 2008. v. 1. p. 1-10. 
seja um método digno de lutar com as mesmas armas que as ciências da natureza. É preciso, também, ir além da relação entre o sujeito e o objeto e se interrogar sobre o ser, sobre o ser-no-mundo. Nesse sentido, Ricoeur acorda com Heidegger que o ser investigado é o ser que existe compreendendo. Mas, diferentemente de Heidegger, Ricoeur, antes de subordinar o conhecimento histórico à compreensão ontológica, buscou demonstrar como se dá esse processo. O caminho escolhido para essa atestação é o da investigação sobre a linguagem, o meio pelo qual a compreensão é um modo de ser, pois é através dela que se poderá elucidar uma semântica do conceito de interpretação. Essa semântica se constitui em torno do tema da significação, da multiplicidade de sentidos e de sua capacidade simbólica. O objetivo de Ricoeur era mostrar que a compreensão de expressões multívocas ou simbólicas é um momento da compreensão de si, por isso, ele defende que o elemento comum a toda atividade interpretante, da exegese à psicanálise, é o duplo sentido ou o múltiplo sentido, que tem como função, de uma maneira geral, mostrar escondendo. A essas expressões multívocas, Ricoeur denomina-as simbólicas. Para ele, é símbolo toda a estrutura de significação onde um sentido direto, primário, literal, designa, a mais, outro sentido indireto, secundário, figurado, que só pode ser compreendido através do primei$\mathrm{ro}^{2}$. A partir da definição do símbolo como algo que está no lugar de outra coisa e que, portanto, engendra a reflexão acerca dessa segunda referência, tem-se o paradigma da hermenêutica da suspeita, ou seja, o símbolo como algo que faz "pensar mais", para além do dado primeiro. Este é, por excelência, o objeto da investigação acerca da linguagem.

Ricoeur, analisando a estrutura e o funcionamento das narrativas ficcionais identifica o processo da "tríplice mimesis". A primeira mimesis é a pré-figuração, ou seja, é a pré-compreensão comum do mundo no ato interpretativo. A segunda mimesis é a configuração, que responde ao anseio de concordância temporal do sujeito. Trata-se ainda da recepção e

2. Cf. RICOEUR, Paul. Le conflit des interprétations - essais d'herméneutique. Paris: Éditions du Seuil, 1969. 
do ato de depreensão e compreensão do agenciamento das ações e do seguimento dessas, como fatos, até a peripécia, ou seja, a mudança de fortuna (tragédia). Ao agenciamento dos fatos Ricoeur denomina de concordância e aos reveses de discordância. A configuração é o intermédio entre a pré -iguração e a refiguração e representa a terceira mimesis. É na refiguração que se dá a junção entre o mundo do texto e o mundo do leitor, visto que é no ato de leitura que esse primeiro se manifesta. Ao que tudo indica, Ricoeur elaborou o conceito da tríplice mimesis com o foco na recepção. Considerando o fato de que o filósofo dialogou tanto com a semiótica como com a linguística e que partiu do esquema de comunicação descrito por Jakobson, é possível depreender da tríplice mimesis ${ }^{3}$ uma estrutura que comporta três elementos fundamentais da constituição do objeto literário: o autor, a obra e a recepção. Nesse sentido, a pré -iguração é, também, o movimento primeiro da elaboração literária, trata-se da observação, da vivência e da eleição de ações, sujeitos, temporalidade e espacialidade a serem configurados na obra. Em termos literários, representa as escolhas que o escritor faz dos elementos que ele elege no mundo real para serem transformados esteticamente no mundo ficcional da poesia ou da prosa. A configuração pode ser traduzida por trabalho estético; dá-se pela relação entre escritor e obra, mais especificamente, é o trabalho de configuração estética empreendida pelo autor no tratamento dado ao material colhido na pré -iguração. O texto ganha, na configuração, autonomia em relação ao autor e ao contexto, visto que ela constrói um todo heterogêneo que tem por referência o mundo mimetizado, mas que, por outro lado, se distancia dele pela inovação metafórica. Nesse sentido, toda narrativa é uma concordância discordante: "Concordância no sentido da referenciação e discordância no sentido da transformação da linguagem, da inscrição direta do discurso na littera". Como referência primeira que se abre potencialmente para a segunda referência, a narrativa ficcional oferece, à realidade comum, novas pos-

3. Cf. PAUlA, Adna Candido de. "Mimesis Tripartida, Uma Leitura Hermenêutica de 'O Almada' de Machado de Assis". Revista da ANPOLL, v.1, p.109 - 124, 2008, p. 119. 4. RICEEUR, Paul. Réflexion faite: autobiographie intelectuelle. Paris: Esprit, 1995, p. 41. 
sibilidades de ser no mundo. Segundo Olivier $\mathrm{Abel}^{5}$, a leitura não deixa o leitor intacto, pois sua subjetividade é colocada em suspenso por sua exposição ao texto, o qual apresenta a ele novas possibilidades de agir e de sentir. A mudança operada no mundo real só é possível porque o mundo do texto perturba, suspende e reorienta as expectativas prévias do leitor. A narrativa ficcional problematiza o mundo e permite a aparição de outros mundos possíveis. Exatamente, por isso, a interpretação do objeto literário é fundamentada na capacidade de descontextualização deste e recontextualização em diferentes períodos históricos, e por extensão, na ressignificação produzida pelas diferentes comunidades de leitores. O mundo do texto é, pois, o objeto dessa hermenêutica.

Quanto à interpretação desses mundos possíveis dispostos na linguagem, ao contrário de uma proposição que divida os processos explicativos, voltados para o sistema de referência interno, dos compreensivos, voltados para o sistema de referência externo, Ricoeur propõe uma junção entre ambos, onde cada um dos pólos tem peso e valor equivalente, representado pelo slogan: Expliquer plus, c'est comprendre mieux ${ }^{6}$. O procedimento hermenêutico é dividido em etapas e faz o caminho inverso de configuração da tríplice mimese:

"Da primeira vez, a compreensão será uma captação ingênua do sentido do texto enquanto todo. Da segunda, será um modo sofisticado de compreensão apoiada em procedimentos explicativos. No princípio, a compreensão é uma conjectura. No fim, satisfaz o conceito de apropriação (...) como a resposta a uma espécie de distanciação associada à plena objetivação do texto. A explicação surgirá, pois, como a mediação entre dois estágios da compreensão. Se se isolar deste processo concreto, é apenas uma simples abstração, um artefato da metodologia"7.

5. ABEL, Olivier. L'éthique interrogative: herméneutique et problématologie de notre condition langagière. Paris: Presses Universitaires de France, 2000, p. 158.

6. RICOEUR, Paul. Du texte à l'action - essais d'herméneutique II. Paris: Éditions du Seuil, 1986.

7. RICOEUR, Paul. Teoria da interpretação: o discurso e o excesso de significação. Lisboa:

Edições 70, 2000, 86. 
Observa-se que essa hermenêutica reconhece todos os elementos que determinam a natureza e a função do objeto de análise dessa relação interdisciplinar - a linguagem. Para que os sentidos sejam manifestos, é preciso entender a "análise estrutural como um estágio - necessário - entre uma interpretação de superfície e uma interpretação de profundidade, seria então possível localizar a explicação e a compreensão em dois estágios diferentes de um arco hermenêutico único ${ }^{8 "}$

\section{A hermenêutica bíblica e a hermenêutica literária}

A linguagem metafórica literária, que se configura como símbolo, em sua capacidade de ressignificar sempre, exige, para fazer manifestar seus plurais sentidos, um suporte teórico que dê conta de efetuar este círculo hermenêutico único. Para se interpretar a linguagem religiosa, o procedimento deverá ser o mesmo, visto que ela fala e faz falar indefinidamente, ela também é simbólica:

"Ao dizer que o Reino de Deus é o elemento comum a vários modos de discurso, de modo algum pretendo subentender que seja o referente último das parábolas, provérbios ou ditos proclamatórios que falam dessa noção de uma maneira ou de outra. Chamando-o "qualificador" de cada um desses modos de discurso, trata-o como um símbolo que requer uma interpretação capaz de fazer dele uma parte do "sentido" da parábola, do provérbio ou do dito proclamatório. É o "indicador" que aponta para além da estrutura, para além mesmo da dimensão metafórica, e que requer um fator correspondente de radicalidade na "redescrição" da realidade humana"'.

A linguagem teológica-religiosa fornece, assim como a linguagem literária, um conjunto de palavras, de símbolos, de signos e representações que não cessam de significar e ressignificar e que, portanto, necessitam, igualmente, de um sistema interpretativo que respeite sua

8. Ibidem, p. 98.

9. RICOEUR, Paul. A hermenêutica bíblica. Trad. Paulo Meneses. São Paulo: Edições Loyola, 2006, p. 136-137. 
natureza. Segundo Ricoeur, é aplicando esse método à exegese bíblica que se faz aparecer a verdade final: “Esta 'aplicação' longe de submeter a hermenêutica bíblica a uma lei estrangeira, ela a torna própria e a livra de várias ilusões. No princípio, ela a livra da tentação de introduzir prematuramente categorias existenciais de compreensão, para contrabalançar os eventuais excessos da análise estrutural ${ }^{10 "}$.

A hermenêutica geral, proposta por Ricoeur, indica que a etapa necessária entre a explicação estrutural e a compreensão de si é o desenvolvimento do mundo do texto. É ele que forma e transforma, segundo sua intencionalidade, o ser-si do leitor. A implicação teológica para Ricoeur pode ser compreendida em quatro pontos: (i) esta hermenêutica permite manifestar o mundo do ser que é a coisa do texto bíblico; assim, é colocada, acima das disposições de crença ou descrença, a proposição de um mundo, o mundo novo sobre o qual fala a Bíblia, o mundo da nova aliança; (ii) suplanta as questões sobre a inspiração das Escrituras, pois como a Bíblia é considerada uma revelação, isso deve ser dito a respeito da coisa do texto; (iii) o sentido do mundo do texto não legitima nenhum privilégio de princípio por uma instrução que se dirige ao ser individual e, em geral, nenhum privilégio a aspectos personalistas na relação do Homem com Deus; o mundo bíblico tem aspectos cósmicos - pois trata-se de uma criação -, tem aspectos comunitários - pois tratase de um povo -, tem aspectos histórico-culturais -, pois trata-se de Israel, do reino de Deus -, e tem aspecto pessoal; (iv) da mesma forma que o mundo do texto literário é um mundo projetado, que se distancia poeticamente da realidade cotidiana, em linguagem teológica, quando se afirma que o reino de Deus vem, este também é um mundo possível, projetado, que se distancia da realidade cotidiana. Contudo, esta afirmação, para Ricoeur, tem implicações quando se retoma o conceito de fé, ao sentido do compreender-se diante do mundo. O ponto fundamental

10. RICOEUR, Paul. "Herméneutique philosophique et herméneutique biblique" in: Du texte à l'action - essais d'herméneutique II. Paris: Éditions du Seuil, 1986, p. 141. OBS: todas as traduções são livres e de autoria da autora deste artigo. 
que dita a especificidade da hermenêutica bíblica é o nome de Deus, que é tanto o coordenador como o índice da incompletude desse discurso. O nome de Deus "pressupõe o contexto total constituído pelo espaço inteiro de gravitação de narrativas, das profecias, das legislações, dos hinos, etc.; Compreender a palavra 'Deus' é seguir a flecha de sentido desta palavrall". O mesmo ocorre com o nome de "Cristo", que soma às duas funções do nome "Deus", coordenador e índice da incompletude do discurso, o poder de encarnar todas as significações religiosas em um símbolo fundamental: "o símbolo de um amor sacrificial, de um amor mais forte que a morte. É a função da predicação da Cruz e da Ressureição de dar à palavra 'Deus' uma densidade que a palavra 'ser' não recebe mais ${ }^{12}$ ". A hermenêutica bíblica só pode pretender dizer uma coisa única se essa coisa única fala como o mundo do texto que se endereça a nós, como a coisa do texto. Aqui, é preciso retomar a quarta implicação teológica da categoria do mundo do texto, a da apropriação. Ricoeur indica três consequências para a hermenêutica bíblica da relação entre o mundo da obra e a compreensão que o leitor toma de si-mesmo diante do texto: (i) A fé é o limite de toda hermenêutica, ao mesmo tempo em que é a origem não hermenêutica de toda interpretação, visto seu caráter pré-linguístico e hiper-linguístico. A fé é inseparável do movimento de esperança que se clareia o modo de transformar as razões do desespero em razões de esperança, apesar da experiência. Entretanto, a fé não pode estar separada do movimento da interpretação que a eleva à linguagem. A confiança incondicionada, que a fé confere, seria vazia se ela não estivesse apoiada na interpretação, sempre renovada, dos acontecimentos-signos relatados pelas Escrituras: "São esses acontecimentos de entrega que abrem e descobrem o possível mais próprio de minha liberdade e assim torna-se, para mim, a palavra de Deus ${ }^{13}$ ". (ii) A segunda consequência resulta do tipo de distanciamento que a hermenêutica

11. Ibidem, p. 144.

12. Ibidem, p. 144.

13. Ibidem, p. 146. 
bíblica produz na compreensão de si quando essa compreensão é um compreender-se diante do texto. No momento da apresentação de si à coisa do texto, a estrutura da compreensão incorpora a crítica de si, que faz parte integrante da compreensão deste diante do texto. Trata-se, em última instância, de uma hermenêutica da suspeita, que faz parte de toda apropriação de sentido. É através dela que se desconstroem os preconceitos que impedem o mundo do texto de se deixar ser. (iii) A terceira e última consequência vem da hermenêutica da apropriação, é o aspecto positivo do distanciamento de si implicado em toda compreensão de si diante do texto. Trata-se da dimensão criativa do distanciamento que estabelece um tipo de jogo com a realidade: "o jogo aberto também na subjetividade das possibilidades da metamorfose que uma visão puramente moral da subjetividade não permite ver"14. É na imaginação que se forma o ser novo, uma vez que o poder de se deixar tomar por novas possibilidades de ser precede o poder de se decidir e de escolher. A imaginação é a dimensão da subjetividade que responde ao texto como poema: "Quando a distanciação da imaginação responde à distanciação da coisa do texto creuse no coração da realidade, uma poética da existência responde à poética do discurso ${ }^{15}$ ". Esta última consequência é a mais relevante, para Ricoeur, uma vez que coloca a coisa do texto acima da compreensão de si. Para Ricoeur, é à imaginação do sujeito que o texto fala, propondo ao sujeito os figurativos de sua liberação.

Por fim, é preciso considerar, na proposição de Ricoeur dessa aproximação das duas hermenêuticas, a terceira mimesis, a refiguração, esta marca a diferença entre as hermenêuticas literária e bíblica. A comunidade de leitura e de interpretação constitui um dos traços que especificam os relatos bíblicos em relação aos profanos, é ela que atribui aos textos inspirados seu estatuto de escritos fundadores e, em contrapartida, recebe destes textos sua própria identidade histórica. $O$ ato de leitura permite, no nível da configuração (mimesis II) a atualização da poética e da 
narrativa dos textos sagrados e, no nível da mímesis III, a refiguração, que o mundo do leitor seja refigurado pelo mundo do texto. No domínio da interpretação bíblica, distingue-se, portanto, duas hermenêuticas de acordo com as finalidades: (i) a hermenêutica histórico-crítica, filológica, semiótica; (ii) a hermenêutica confessante, eclesial. Esta depende de uma palavra anterior cuja autoridade é conferida pela comunidade eclesial, que tomam os textos sagrados canônicos como aqueles que nomeiam a Deus. Ricoeur não se posiciona rigidamente contra uma pluralidade das interpretações dos textos sagrados, ou das possíveis ressignificações que $o$ ato de leitura pode engendrar. Mas aponta, no artigo "Resposta a David Stewart", este "risco" caso se empreenda, na leitura destes textos, o sistema da hermenêutica geral - compreensão/ explicação/compreensão. Certo controle de uma provável dispersão infinita cabe à comunidade eclesial:

"As barreiras à disseminação encontram-se no papel estruturante exercido pela vida comunitária eclesial (...) uma comunidade histórica interpreta-se a si mesma ao interpretar o tesouro de sua Escritura. É dessa maneira que as comunidades de leitura e de interpretação se constituem, que embora não sendo redutíveis a uma unidade, não correm o perigo de uma dispersão infinita"16.

Percebe-se, aqui, o movimento dialético da filosofia ricoeuriana que faz dialogar e se contaminar mutuamente seu discurso teológico e filosófico, na medida em que a dispersão infinita da interpretação das Escrituras põe em risco sua identidade e seu télos: "A única questão a ser posta é a de saber se nas condições da modernidade - ou da pósmodernidade - à qual a história da leitura da Escritura está submetida, esses velhos textos continuarão a instruir e a ajudar as novas gerações de mortais a viver em conjunto e a compreender-se mutuamente ${ }^{17 "}$. Essa questão reenvia as reflexões de Ricoeur sobre a hermenêutica bíblica

16. RICOEUR, Paul. A hermenêutica biblica. Trad. Paulo Meneses. São Paulo: Edições Loyola, 2006, p. 71.

17. Ibidem, p. 99. 
para aquelas, no plano filosófico, sobre a identidade, sobre a sabedoria prática e sobre a relação entre o "si-mesmo" e o "viver-com", na dimensão da ética.

\section{Considerações Finais}

As considerações feitas, aqui, têm dupla função: apresentar um possível procedimento metodológico que oriente a prática interdisciplinar, entre literatura, teologia e religião, respeitando a natureza dos objetos a serem analisados; e chamar a atenção para a legitimidade das práticas interdisciplinares e da necessidade de se refletir epistemologicamente esses procedimentos. Em um processo dialógico como este, as vozes em questão são ouvidas, há troca, há respeito, há solidariedade e ética. Observa-se que é do interesse das áreas envolvidas e dos agentes que promovem a relação interdisciplinar estabelecerem os limites e as pontes entre esses saberes.

\section{Bibliografia}

$A B E L$, Olivier. L'éthique interrogative: herméneutique et problématologie de notre condition langagière. Paris: Presses Universitaires de France, 2000, p. 158.

COMMISSION BIBLIQUE PONTIFICALE. L'interprétation de la Bible dans l'église. Paris, 1993. Apud RICOEUR, Paul. A hermenêutica bíblica. Trad. Paulo Meneses. São Paulo: Edições Loyola, 2006.

PAULA, Adna Candido de. "A Teia Dialógica da Teoria Literária: uma proposição hermenêutica". In: XI Congresso Internacional da Associação Brasileira de Literatura Comparada, 2008, São Paulo. Anais do XI Congresso Internacional da ABRALIC. São Paulo: ABRALIC, 2008.

. "Mimesis Tripartida, Uma Leitura Hermenêutica de 'O Almada' de Machado de Assis». In: Revista da ANPOLL , v.1, p.109 - 124, 2008.

RICCEUR, Paul. A hermenêutica bíblica. Trad. Paulo Meneses. São Paulo: Edições Loyola, 2006.

. Du texte à l'action - essais d'herméneutique II. Paris: Éditions du Seuil, 1986.

. "Herméneutique philosophique et herméneutique biblique" in: Du tex- 
te à l'action - essais d'herméneutique II. Paris: Éditions du Seuil, 1986. . Le conflit des interprétations - essais d'herméneutique. Paris: Éditions du Seuil, 1969.

. Réflexion faite: autobiographie intelectuelle. Paris: Esprit, 1995.

- Teoria da interpretação: o discurso e o excesso de significação. Lisboa: Edições 70, 2000. 